\title{
Eldivan İlçesinde Yaşayan Yaşlılara İnformal Bakım Verenlerin Bakım Yükleri ${ }^{1}$
}

\author{
DOI: 10.26466/opus.926095
}

\author{
*

\section{Tahsin Barıs Değer* - Yadigar Ordu**} \\ * Dr. Öğr. Üyesi, Çankırı Karatekin Üniversitesi, Sağlık Bilimleri Fakültesi, Çankırı/Türkiye \\ E-Posta: drbarisdeger@gmail.com \\ ORCID: $\quad 0000-0002-4231-0782$ \\ ** Öğr. Gör, Çankırı Karatekin Üniversitesi, Eldivan Sağlık Hizmetleri MYO, Çankırı/Türkiye \\ E-Posta: yadigarordu2818@gmail.com \\ ORCID: $\quad$ 0000-0002-4060-0487
}

Öz

Çalışmada Eldivan ilçesinde yaşayan yaşlılara bakım veren aile bireylerinin (informal bakım veren) bakım yükünü tespit etmek amaçlandı. Bakım veren katılımcılara mahalle muhtarlarından destek alınarak ulaşıldı ve görüşmeler yüz yüze gerçekleştirildi. Katılımcıların bakım yükü Zarit Bakım Verme Yükü Ölçeği (ZBYÖ) kullanılarak tespit edildi. Yaşllların ve bakım verenlerin sosyodemografik, sağllk ve sosyal verilerine araştırmacılar tarafindan tasarlanan sorularla ulaşıldı. Yaşlıların bağımlılık seviyeleri Katz Günlük Yaşam Aktiviteleri Ölçeği ile tespit edildi. Bakım verenlere ait ZBYÖ puan

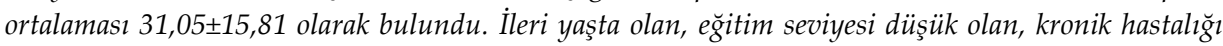
bulunan, kronik hastalık ve kullanılan ilaç sayısı fazla olan, uyku problemi yaşayan ve bir işte çalışmıyor olan bakım verenlerde bakım yükü yüksek, evden sık sık dışarıya çıkan, düzenli yürüyüş ve spor yapan, ailesi ile vakit geçiren ve bilgisayar kullanan bakım verenlerde bakım yükü düşük olarak bulundu.Yatalak olan, bir engeli bulunan ve idrarm tutamayan (inkontinans) yaşlilara bakım verenlerde bakım yükü yüksek olarak bulundu. Yaşlının bă̆gmlılığı artış gösterdikçe bakım verenin yükünün de artırdı̆̆̆ tespit edildi.

Anahtar Kelimeler: Bakım Yükü, Bakım Veren, Yaşlı Bakımı.

\footnotetext{
${ }^{1}$ Çalışma, Çankırı Karatekin Üniversitesi Bilimsel Araştırmalar Projesi (BAP) kapsamında desteklenmiştir (Proje No: EYO 080120B27)
} 


\title{
Care Burden of Informal Caregivers of the Elderly Living in Eldivan District
}

*

\begin{abstract}
In the study, it was aimed to determine the care burden of family members (informal caregivers) who care for the elderly living in Eldivan district. Caregiving participants were reached with the support of the neighborhood headmen and the interviews were held face to face. The care burden of the participants was determined using the Zarit Care Burden Scale (ZCBS). Sociodemographic, health and social data of the elderly and their caregivers were reached with questions designed by the researchers. The addiction levels of the elderly were determined with the Katz Daily Living Activities Scale. The mean ZCBS score of the caregivers was found to be $31.05 \pm 15.81$. Care burden was found to be high in caregivers who are aged adult, have low education level, have chronic diseases, have the high number of drugs used, have sleep problems and are not working, and to be low in caregivers who go out from home often, walks regularly, spend time with their family and use computers. Care burden was found to be high in the caregivers who care for the bedridden, disabled, and incontinent elderly. It was determined that as the dependence of the elderly increased, the burden of the caregiver also increased.
\end{abstract}

Key Words: Care Burden, Caregiver, Elderly Care. 


\section{Giriş}

Dünyada ve ülkemizde son yıllarda yaşanan en büyük demografik değişim nüfusun yaşlanmasıdır. Doğum ve ölüm oranlarındaki azalma, ortanca yaştaki artış, doğuşta beklenen yaşam süresindeki artış ve yaşlı nüfusun toplam nüfus içerisindeki oranının artışı Türkiye'de nüfus yaşlanmasının ne kadar hızlı olduğunun göstergeleridir. En önemli göstergelerden birisi ise, 2018 yılında \%12,9 olan yaşlı bağımlılık oranının 2080 yılında \%43,6 olarak öngörülmesidir (Bostan ve Sertkaya Doğan, 2019, s.82). Yaşlı bağımlılık oranı yaşlı nüfusun çalışan nüfusa oranını ifade etmektedir. Bu orandaki artış gelecekte bakım ihtiyacı olan yaşlı sayısının ve bakım süresinin artacağı anlamına gelmekle birlikte, bakım veren ihtiyacındaki artışı da beraberinde getirecektir.

Bakım, kelime anlamı olarak; bir şeyin daha iyiye gitmesi veya iyi bir şekilde devam etmesi için harcanan emek, birine beslenme, giyinme gibi günlük yaşam aktivitelerini gerçekleştirmede destek verme işi olarak tanımlanmaktadır (Türk Dil Kurumu Sözlükleri, 2021). Bakım veren ise, bakıma ihtiyacı olan yaşlının yaşadığı sorunlara göre ona yardım eden, destek sağlayan kişi olarak tanımlanır. Buradaki destek en yaygın oranda duygusal destek olmakla birlikte ulaşım, alışveriş yapmak, ev işleri yapmak, sosyal hizmet ve sağlık hizmeti sağlayıcılarından gelen yardımı koordine etmek, ilaçların verilmesi ve izlenmesi gibi rutin sağlık bakımı, banyo, beslenme, tuvalet ve giyinme gibi kişisel bakım, nezaret etme, finansal asistanlık ve ortak bir evin paylaşımı olarak sıralanabilir (Toseland, Smith, ve McCallion, 2001, s.550). Bakım verme, formal ve informal olmak üzere ikiye ayrılır. Formal bakım evde veya bakım merkezlerinde sağlık veya sosyal bakım hizmetleri sağlayan meslek mensuplarının verdiği bakımdır. Bunlar; hemşire, fizyoterapist, sosyal çalışmacı, evde hasta bakım veya yaşlı bakım teknikerleridir. İnformal bakım ise; bakım ihtiyacı olan yaşlının eşi, çocuğu, akrabası veya komşusu tarafından verilen bakımdır (Türken Gel ve Tokur Keskin, 2017, s.268).

Bakım verme, yaşlıya bakım veren bireyler açısından hem olumlu hem de olumsuz boyutları olan bir deneyimdir. Olumlu yanları; yaşlı ile bakım veren arasındaki sevgi ve bağlılığın artması, bakım verene anlam bulma, kişisel gelişim, çevresindeki insanlardan taktir görme, öz saygısında artma, duygusal açıdan kendini iyi hissetme gibi özellikler 
kazandırmasıdır. Olumsuz yanları ise; informal bakım vericilere stres, fiziksel rahatsızlıklar, sosyal hayata iştirak edememe, aile fertleri ile ilişkilerde, ekonomik ve iş yaşamında pek çok zorluk yaşamaları olarak belirtilmiştir (İnci, 2006, s.7-10).

Bakım yükü Amerikalı bir Gerontolog olan Zarit tarafından, yaşlı bireye bakan aile üyesinin sağllk, psikolojik, sosyal ve ekonomik yönlerden yaşadığı rahatsızlık olarak tanımlanmıştır (Misra, Oswal, ve Patel, 2020, s.445). Başka bir ifadeyle bakım veren yükü, bakım sağlamanın bakıcıların sosyal, mesleki ve kişisel rolleri üzerindeki etkisine olumsuz bir tepki olarak da tanımlanmaktadır. Bazı yazarlar bakım verenin nesnel ve öznel yükünü birbirinden ayırmaktadır. Nesnel (objektif) yük; aile ve bakım verenin yaşamında meydana gelen değişimleri kapsamaktadır. Bakım verenin davranışları ve fiziksel semptomlarındaki değişikliklerin yanı sıra, ev rutinindeki, aile ve sosyal ilişkilerdeki, işteki ve boş zamanlarındaki değişiklikleri de içine alır. Bakım verenin fiziksel sağlığındaki değişiklikler de bu grubun içinde değerlendirilir (Chan, 2010, s. 471). Öznel (subjektif) yük ise; bakım verenin içinde bulunduğu durum nedeniyle duygularında ortaya çıkan tepkilerdir. Dışarıdan bakıldığında daha az belirgin olan bu değişiklikler; endişe, kaygı, hayal kırıklığı ve sinirlilik gibi duygulardır. (Honea vd., 2008, s.508).

Bakım verme yükü çok boyutlu bir fenomendir. Bakım veren-yaşlı ikilisinin ilişki türü, bakım verenin özellikleri, bakımdaki sosyal desteğin mevcudiyeti, yaşlının sorunlu davranışları, bakım verenin başa çıkma stratejisi ve bakım yönetimi bakım yükünün boyutlarından bazılarıdır (Chan, 2010, s.471). Yaşlıya informal bakım veren bireyler becerikli, duygusal olarak dayanıklı veya bakımı en iyi verebilecek kişiler oldukları için değil aile bireyi, evlat, eş olma sorumluluğu üstlendiklerinden bakım vermeyi kabul ederler. Burada duygusal bağlar, sevgi, sayg1, bağl1lık, empati kurma, suçluluk duygusundan kurtulma isteği, değer yargıları, inançları ve yaşlı ile beraber geçirilmiş yıllar önem kazanmaktadır (Erdem, 2010, s.103).

Bu çalışmada, Çankırı'nın Eldivan ilçesinde yaşayan yaşlılara informal (aile bireyi) bakım verenlerde bakım yükünü belirlemek amaçlandı. İlçe tarihinde daha önce yaşlılara bakım verenlerle ilgili bir çalışma yapılmamıştı. Bu çalışma, bir ilçenin kendi sosyo-kültürel yapısı 
içerisinde yaşlılara bakım verenlerdeki yükü ve bu yükü etkileyen faktörleri ortaya çıkarmak, yaşlı bakımına bakım veren penceresinden bakarak toplumda farkındalık oluşturmak ve ortaya çıkacak raporla ilçede kurumlara yol gösterici olmak için gerçekleştirildi.

\section{Yöntem}

\section{Örneklem}

İlçede yaşayan 65 yaş ve üstü bireylere bakım veren kişi sayısı bilinmemekteydi, bu nedenle çalışmada örneklem sınırlaması yoktu, ulaşılabilen tüm bakım verenlere ulaşılmaya çalışıldı

İlçede bakım verenlere ulaşmada sırasıyla üç yöntem kullanıldı.

Birinci yöntemde, Eldivan Kaymakamlığı Sosyal Yardımlaşma ve Dayanışma Vakfı'na kayıtlı olan ve bakım aylığı alan kişilere ulaşıldı. Kayıtlarda 22 kişi olan bakım aylığı alanların 13 kişisi 65 yaş altı ve engelli bireylere bakanlardan oluşuyordu ve çalışma dışı bırakıldı. Kalan 9 kişi çalışmaya gönüllü olarak katılmayı kabul ettikleri için vakıf tarafından kendilerinden randevu alındı ve araştırmacılar tarafından yüz yüze görüşmeler yapılarak çalışmaya dahil edildi.

İkinci yöntemde, Adrese Dayalı Nüfus Kayıt Sistemi kayıtlarından rastgele örneklem metodu ile seçilen yaşlıların evlerine ziyaretler gerçekleştirildi. Ziyaret edilen 90 yaşlı içerisinde bakım alan yaşlı sayısı 10 kişi olduğundan çalışmaya 10 bakım veren dahil edildi, geriye kalan 80 yaşlı yalnız yaşıyor veya eşi ile beraber yaşıyordu, herhangi bir aile bireyinden bakım almıyordu.

Üçüncü yöntemde, ilçe merkezindeki mahalle muhtarlarından destek alındı. Muhtarlar kendi mahallelerinde yaşlıya bakım verenlere ulaşmada araştırmacılara yardımcı oldular. Muhtarların desteği ile yaşlıya bakım veren 55 kişi daha çalışmaya dahil edildi. Araştırmanın içleme ölçütleri, ilçede 65 yaş ve üstü bir yaşlıya bakım veren, çalışmaya gönüllü olarak katılmayı kabul eden ve bilgilendirilmiş olur formunu imzalayan bireylerin çalışmaya dahil edilmesiydi. Bakıma ihtiyacı olan yaşlıların bir bölümünün Çankırı, Ankara gibi illerde çocuklarının yanında yaşadığı ve bakıldığı bilgisine ulaşıldı. Çalışmalar yüz yüze anket görüşmesi olarak 
gerçekleştirildi. Toplamda ilçede yaşayan 74 yaşlı ve 74 bakım veren çalışmanın örneklemini oluşturdu.

İlçe, iş ve istihdam olanağı kısıtlı olan küçük bir Anadolu kasabasıydı. Gençler ve yetişkinler iş nedeniyle genellikle Çankırı, Ankara gibi daha büyük kentlere göç etmişti. İlçede yaşlılar genellikle eşleri ile beraber veya yalnız yaşıyorlardı. Bakım ihtiyacı olan yaşlılar, çocukları veya kendilerine bakabilecek aile bireylerinden bazıları ilçede yaşıyor ise Eldivan'da kalıyor, aksi takdirde çocuklarının yanına göç etmek zorunda kalıyorlardı. İlçede yaşlılarına bakım verenler informal (aile bireyi) bakıcılardan oluşuyordu.

Çalışma kesitsel olarak tasarlanmıştır. Çalışmaya 2020 yılı mart ayında başlanmış ancak COVID-19 pandemisi ve 21 Mart 2020 tarihinde ülkemizde yaşlılara sokağa çıkma yasağ çalışmaya ara verilmek zorunda kalınmıştır. Yaşlılara yönelik sokağa çıkma yasağı yaz aylarında kaldırılmış, ağustos ve eylül aylarında çalışmaya kaldığ 1 yerden devam edilmiş ve toplam iki ay içerisinde çalışma tamamlanmıştır. Çalışma yaşlılarla ve onlara bakım verenleri ile maske, mesafe ve hijyen kurallarına riayet edilerek gerçekleştirilmiştir. Görüşmeler özellikle evlerin bahçelerinde, açık havada yapılmıştır. Eldivan ilçesinin genellikle bahçeli evlerden oluşması çalışmanın daha rahat yapılmasına olanak sağlamıştır.

\section{Veri Toplama Yöntemi ve Değerlendirme}

Veri Toplama Araçları olarak; Bakım verene yönelik olan Bakım Veren Tanıtım Formu ve Zarit Bakım Verme Yükü Ölçeği (ZBYÖ) olmak üzere iki adet, yaşlıya yönelik olan Yaşlı Tanıtım Formu ve Katz Günlük Yaşam Aktiviteleri Ölçeği olmak üzere iki adet, toplam dört adet ayrı form kullanıldi.

Bakım verene yönelik kullanılan formlardan ilki Bakım Veren Tanıtım Formu'dur. Araştırmacılar tarafından oluşturulan bu form bakım verenlere ait sosyo-demografik, sağlık ve sosyal verilerin bulunduğu tanıtım formudur. Bu formda ayrıca bakım verenin ilgi duyduğu sanatsal ve sosyal alanlarla birlikte hobileri, yaşam tarzları, aile ilşkileri ve alışkanlıkları ile ilgili verilerde bulunmaktadır. İkinci form ZBYÖ'dir. Bu ölçekle araştırmanın konusu olan bakım yükü tespit edildi. Bu ölçek ilk 
defa Zarit ve arkadaşları tarafından yaşlılara bakım verenlerdeki bakım yükünü ölçmek için geliştirilmiştir (Zarit, Reever, ve Bach-Peterson, 1980). $\mathrm{Bu}$ ölçeğin ülkemizdeki yaşlıların bakım verenlerine yönelik Türkçe geçerlilik ve güvenilirlik çalışması yapılmıştır (İnci ve Erdem, 2008). Bakım veren yaşlı ilişkisi, bakım verenin sosyal hayatı, sağlık ve psikolojik durumu, bakım verene ekonomik yükü gibi birçok alanı değerlendiren 22 maddelik Likert (0-4) tipi bir ölçektir. Puanlama; asla (0 puan), nadiren (1 puan), bazen (2 puan), sik sik (3 puan), hemen her zaman (4 puan) şeklindedir. Her bireyin toplam puanı 0-88 arasında değişmektedir. Yüksek puan yüksek derecedeki bakım yükünü göstermektedir (Uşarel ve Işık, 2017, s.206). Bakım yükünün dereceleri ölçekten alınan puanlara göre kategorize edilmiştir. ZBYÖ puanı 0-20 arası yükün olmadığ1 veya hafif derecede bir yükün olduğu anlamına gelmektedir. 20-40 puan arası hafiforta derecede yükün olduğu, 40-60 puan arası orta-ağır derecede yükün olduğu ve 60-88 puan arası ise; ağır derecede bakım yükünün mevcut olduğu anlamında değerlendirilmektedir (James vd., 2021, s.175).

Yaşlıya yönelik kullanılan formlardan ilki Yaşlı Tanıtım Formu'dur. Bu formda yaşlılara ait sosyodemografik ve sağlık verileri bulunmaktadır. Form araştırmacılar tarafından literatür taranarak oluşturulmuştur (Erdem, 2010; İnci, 2006; Shrestha vd., 2020). İkincisi ise Katz Günlük Yaşam Aktiviteleri Ölçeği'dir. Katz tarafından geliştirilen ve yaşlının bakıma muhtaçlık seviyesini belirleyen ölçektir (Katz, 1983). Ölçeğin Türkçe geçerlik ve güvenirlik çalışmaları yapılmıştır (Arık vd., 2015; Pehlivanoğlu, Özkan, Balcıŏ̆lu, Bilge ve Ünlüoğlu, 2018). Katz ölçeği yıkanma, giyinme, tuvalete gitme, yer değiştirme, mesane ve bağırsak kontrolü, beslenme alt başlıklarını içerir. Her bir faaliyeti yardım almadan yapabiliyorsa 1 puan, yapamıyorsa 0 puan verilir. Alınan en yüksek puan (6) yaşlıda bağımlılığın olmadığını, 4 puan orta derecede bağımlılığın olduğunu, 2 puan ve altı tam bakıma muhtaçlığın olduğunu gösterir (Soysal, 2017, s.34). Çalışmamızda yaşlının bağımlılığı bu ölçek ile tespit edildi.

Çalışmaya başlamadan önce Çankırı Karatekin Üniversitesi Etik Kurulundan onay alınmıştır (Toplantı No: 2019/144, Karar No: 144, Karar Tarihi: 23.10.2019). Çalışma, Eldivan Kaymakamlığı iş birliği (Sayı: SYDV/2020/96, Tarih: 10.03.2020) ve Çankırı Karatekin Üniversitesi Bilimsel Araştırmalar Projesi (EYO 080120B27) desteği ile 
gerçekleştirilmiştir. Çalışma Helsinki Bildirgesine ve uluslararası etik kurallara uygun bir şekilde yürütülmüştür. Çalışmaya katılan tüm katılımcılardan ıslak imzalı bilgilendirilmiş onam alınmıştır.

\section{İstatistiksel Analiz}

Ölçek puanlarının normal dağılıma uygunluğu Shaphiro wilk testi ile kontrol edilmiş, ölçek sorularının iki kategorili karşılaştırılmasında Mann Whitney U testi, ikiden fazla kategorinin karşılaştırılmasında ise Kruskal Wallis ve Dunn çoklu karşılaştırma testleri kullanılmıştır. Sayısal değişkenler arasındaki ilişkilerin test edilmesinde Spearman korelasyon katsayısı kullanılmıştır. İstatistiksel analizler için SPSS for Windows version 24.0 paket programı kullanılmış ve $\mathrm{P}<0.05$ istatistiksel olarak anlamlı kabul edilmiştir.

Çalışmanın bağımlı değişkeni bakım verenin Zarit Bakım Verme Yükü ölçek puanıdır. Bağımsız değişkenler ise; bakım verenin sosyodemografik, sağlık, sosyal, sanatsal, yaşam tarzı verileri, yaşlının sosyodemografik, sağlık verileri ve yaşlının Katz Günlük Yaşam Aktiviteleri Ölçeği puanıdır.

\section{Bulgular}

Çalışmada bakım verenlerin yaş ortalamaları 49,87 \pm 13,55 olarak bulundu. Katılımcıların hepsi informal (aile üyesi) bakım verenlerden oluşuyordu. ZBYÖ puan ortalaması 31,05 \pm 15,81 olarak belirlendi ve ilçede yaşlılarına bakım verenlerde hafif-orta derecede bakım yükü mevcut olduğu tespit edildi. ZBYÖ puanı medyan (ortanca) değeri 26,5 (8 - 65) olarak bulundu.

Bakım verenlerin sosyodemografik verilerinin bakım yükü üzerine etkisi yaş ve eğitim durumu değişkenlerinde anlamlıydı. Bakım verenlerden ileri yaşta olanların bakım yükleri yaşı daha genç olanlara göre yüksek bulundu $(<0,05)$. Üniversite mezunu katılımclarda bakım yükü diğer eğitim seviyelerindeki katılımcılara göre daha düşüktü. Lise ve ilköğretim mezunları da okuma yazma bilmeyen katılımcılara göre daha düşük bakım yüküne sahipti $(<0,05)$. Eşine bakım verenlerde bakım yükü anne, baba, kayınvalide, kayınbaba, dede, nineye bakım 
verenlerden yüksekti $(<0,05)$. Yatalak olan yaşlıya bakanlarda en yüksek bakım yükü bulunurken, engeli olan yaşlılara ve ihtiyacı olan yaşlılara bakım verenlerde diğer bakım nedenlerine göre daha yüksek bakım yükü bulundu $(<0,05)$. (Tablo 1$)$.

Tablo 1. Bakım Verenlerin Sosyodemografik Verileri ile Bakıma Ait Verilerin Bakım Yükü Üzerine Etkisi

\begin{tabular}{|c|c|c|c|c|c|}
\hline Değişken & Grup & $\mathbf{N}$ & Zarit-Ortanca & Test İst. & $p$ \\
\hline \multirow[t]{4}{*}{ Yaş } & 18-34 yaş & 9 & $20(11-49)^{a}$ & $\mathrm{X}^{2}=17.30$ & $0,001^{*}$ \\
\hline & $35-49$ yaş & 27 & $21(8-61)^{a}$ & & \\
\hline & 50-64 yaş & 25 & $33(13-65)^{b}$ & & \\
\hline & $65+$ & 13 & $54(19-62)^{b}$ & & \\
\hline \multirow[t]{2}{*}{ Cinsiyet } & Kadın & 49 & $28(11-63)$ & $Z=-0,21$ & 0,832 \\
\hline & Erkek & 25 & $25(8-65)$ & & \\
\hline \multirow[t]{2}{*}{ Medeni durum } & Evli & 57 & $28(11-63)$ & $Z=-0,41$ & 0,676 \\
\hline & Bekar & 17 & $25(8-65)$ & & \\
\hline \multirow[t]{4}{*}{ Eğitim } & Okur-yazar değil & 9 & $37(28-63)^{a}$ & $X^{2}=12,32$ & $0,006^{*}$ \\
\hline & İlköğretim & 26 & $28(11-61)^{b}$ & & \\
\hline & Lise & 25 & $26(13-65)^{b}$ & & \\
\hline & Üniversite & 14 & $17,5(8-47)^{c}$ & & \\
\hline \multirow[t]{2}{*}{ Sosyal güvence } & Var & 65 & $26(11-65)$ & $Z=1,68$ & 0,093 \\
\hline & Yok & 9 & $41(8-63)$ & & \\
\hline Kiminle & Eşi/çocuğu & 19 & $33(11-62)$ & $X^{2}=2,25$ & 0,325 \\
\hline \multirow[t]{2}{*}{ yaşıyor? } & Eşi/çocuğu-yaşlı & 41 & $24(11-63)$ & & \\
\hline & Yaşlı & 14 & $25,5(8-65)$ & & \\
\hline \multirow[t]{5}{*}{ Yaşlı kim? } & Anne & 28 & $27(11-61)^{\mathrm{a}}$ & $X^{2}=12,67$ & $0,013^{*}$ \\
\hline & Baba & 13 & $25(8-65)^{a}$ & & \\
\hline & Eşi & 11 & $43(16-62)^{\mathrm{b}}$ & & \\
\hline & Kayın ana/baba & 16 & $24,5(11-63)^{a}$ & & \\
\hline & Dede-nine & 6 & $15(11-20)^{c}$ & & \\
\hline \multirow[t]{7}{*}{ Bakım nedeni } & Yaşlılık & 16 & $20(11-65)^{a}$ & $X^{2}=13,02$ & $0,043^{*}$ \\
\hline & Yalnızlık & 7 & $20(16-24)^{\mathrm{a}}$ & & \\
\hline & Yatalak & 2 & $47,5(33-62)^{b}$ & & \\
\hline & Aynı evde yaşam & 3 & $25(8-28)$ & & \\
\hline & İhtiyaç & 11 & $39(19-60)^{c}$ & & \\
\hline & Engel & 11 & $43(16-60)^{c}$ & & \\
\hline & Sağlık-hastalık & 24 & $28(11-63)$ & & \\
\hline \multirow{4}{*}{$\begin{array}{l}\text { Bakım süresi } \\
\text { (yıl) }\end{array}$} & 5 yıldan az & 18 & $23,5(11-62)$ & $X^{2}=1,30$ & 0,727 \\
\hline & 5-9 yıl arası & 12 & $27(16-48)$ & & \\
\hline & 10-19 yıl & 23 & $26(13-59)$ & & \\
\hline & 20 ve uzun & 11 & $27(15-63)$ & & \\
\hline
\end{tabular}

${ }^{*} 0,05$ düzeyinde anlaml, Z: Mann Whitney U testi, $X^{2}$ : Kruskal Wallis testi, a,b,c,d,e Farklı harfli gruplar arasında istatistiksel olarak anlamlılı vardır, Zarit-Ortanca: Zarit puanı Ortanca değeri (Minimum - Maximum değerler). 
Tablo 2. Bakım Verenlerin Sağlık-Sosyal Verilerinin Bakım Yükü Üzerindeki Etkisi

\begin{tabular}{|c|c|c|c|c|c|}
\hline Değişken & Grup & $\mathbf{N}$ & Zarit-Ortanca & Test İst. & $p$ \\
\hline \multirow[t]{2}{*}{ Kronik Hastalık } & Var & 30 & $30(8-65)$ & $Z=-1,995$ & $0,046^{*}$ \\
\hline & Yok & 44 & $23(11-61)$ & & \\
\hline \multirow[t]{3}{*}{ Hast. sayısı } & Yok & 44 & $23(11-61)^{a}$ & $X^{2}=6,131$ & $0,047^{*}$ \\
\hline & 1 tane & 18 & $26(8-65)$ & & \\
\hline & 2 ve üzeri & 12 & $39(19-60)^{b}$ & & \\
\hline \multirow{3}{*}{$\begin{array}{l}\text { Kullanılan ilaç } \\
\text { sayısı }\end{array}$} & Kullanmayan & 49 & $24(11-61)^{a}$ & $X^{2}=7,071$ & $0,029 *$ \\
\hline & 1 ilaç & 11 & $25(8-63)^{a}$ & & \\
\hline & 2 ilaç ve üzeri & 14 & $41(16-65)^{b}$ & & \\
\hline \multirow[t]{3}{*}{ BKI } & $<25$ & 24 & $28(8-65)$ & $X^{2}=0,207$ & 0,902 \\
\hline & $25-29,9$ & 33 & $26(12-63)$ & & \\
\hline & $30-34,9$ & 12 & $30(11-54)$ & & \\
\hline \multirow[t]{3}{*}{ Uyku sorunu } & Yok & 51 & $25(11-63)^{a}$ & $X^{2}=6,081$ & $0,048^{*}$ \\
\hline & Uykusuzluk & 20 & $40(8-65)^{b}$ & & \\
\hline & Sik uyuma & 3 & $14(11-61)$ & & \\
\hline \multirow[t]{2}{*}{ Çalışıyormu? } & Evet & 18 & $20(11-61)$ & $Z=1,961$ & $0,050^{*}$ \\
\hline & Hayır & 56 & $28(8-65)$ & & \\
\hline Bilgisayar & Evet & 35 & $21(8-65)$ & $Z=2,747$ & $0,006^{*}$ \\
\hline kullanma & Hayır & 39 & $32(12-63)$ & & \\
\hline Sanatla & Evet & 18 & $29(11-56)$ & $Z=-0,025$ & 0,980 \\
\hline ilgilenme & Hayır & 56 & $26,5(8-65)$ & & \\
\hline \multirow{3}{*}{$\begin{array}{l}\text { Müzik dinleme } \\
\text { sıklığı }\end{array}$} & Sık sık & 25 & $20(11-65)$ & $X^{2}=3,046$ & 0,218 \\
\hline & Nadiren & 41 & $28(8-62)$ & & \\
\hline & Hiçbir zaman & 8 & $35(16-55)$ & & \\
\hline \multirow{3}{*}{$\begin{array}{l}\text { Evden çıkma } \\
\text { sıklığı }\end{array}$} & Sıklıkla & 32 & $21(11-61)^{a}$ & $X^{2}=6,266$ & $0,044^{*}$ \\
\hline & Nadiren & 40 & $30(8-65)^{b}$ & & \\
\hline & Asla & 2 & $36,5(23-50)$ & & \\
\hline \multirow[t]{2}{*}{ Yürüyüşs/spor } & Evet & 39 & $21(11-60)$ & $Z=3,056$ & $0,002^{*}$ \\
\hline & Hayır & 35 & $37(8-65)$ & & \\
\hline \multirow{3}{*}{$\begin{array}{l}\text { Çocuklarla } \\
\text { ilgilenme }\end{array}$} & Evet & 41 & $21(11-63)$ & $X^{2}=5,062$ & 0,080 \\
\hline & Hayır & 21 & $28(8-65)$ & & \\
\hline & Arasıra & 12 & $41,5(13-61)$ & & \\
\hline \multirow{5}{*}{$\begin{array}{l}\text { Aile ile vakit } \\
\text { geçirme } \\
\text { Komşu ile vakit } \\
\text { geçirme }\end{array}$} & Evet & 29 & $23(11-60)$ & $Z=1,962$ & $0,050^{*}$ \\
\hline & Hayır & 45 & $31(8-65)$ & & \\
\hline & Evet & 39 & $23(11-60)$ & $X^{2}=2,254$ & 0,324 \\
\hline & Hayır & 9 & $28(14-65)$ & & \\
\hline & Arasıra & 26 & $31,5(8-63)$ & & \\
\hline
\end{tabular}

Kronik hastalığı olan katılımcılarda bakım yükü hastalığı olmayanlara göre yüksekti $(<0,05)$. İki veya daha fazla kronik hastalığa sahip olan ve her gün düzenli olarak iki veya daha fazla ilaç kullanan katılımcılarda bakım yükü, hastalığı olmayanlara ve ilaç kullanmayanlara göre daha yüksekti $(<0,05)$. Uykusuzluk çekenlerde uyku problem olmayanlara göre bakım yükü yüksekti $(<0,05)$. Bir işte çalışmayan bakım verenlerde 
çalışanlara göre bakım yükü yüksekti $(<0,05)$. Bilgisayar kullanamayan katılımcılarda kullananlara göre bakım yükü yüksekti $(<0,05)$. Sıklıkla evden dışarıya çıkanlarda, düzenli yürüyüş veya spor yapanlarda, boş zamanlarında ailesi ile vakit geçirenlerde bakım yükü daha hafif olarak belirlendi $(<0,05)$. (Tablo 2$)$.

Çalışmada bakım alan yaşlıların yaş ortalaması 80,86 \pm 8,79 olarak bulundu. Bakım alan yaşlının sosyodemografik ve sağlık verilerinin bakım veren yükü üzerine etkisine bakıldığında; engeli olan yaşlılara bakım verenlerde engeli olmayan yaşlılara bakım verenlere göre bakım yükü daha yüksek bulundu $(<0,05)$. İnkontinans (idrarını tutamayan) olan yaşlılara bakım verenlerde bakım yükü, inkontinans olmayan yaşlılara bakım verenlere göre daha yüksek bulundu $(<0,05)$. Bakım alan yaşlıların diğer sosyodemografik verilerinin bakım verenlerdeki bakım yükünü etkilemediği belirlendi (Tablo 3).

Bakım verenlerdeki bakım yükünü ölçen Zarit Bakım Verme Yükü Ölçek puanları ile yaşlılardaki bağımlılığı ölçen Katz Günlük Yaşam Aktiviteleri Ölçek puanları arasında negatif yönde orta düzeyde anlamlı bir korelasyon saptandı $(r=-0,469, P=0,001)$. Yaşlılarda bağımlılık seviyesi arttıkça (Katz puanı azaldıkça) bakım verenlerde bakım yükünün yükseldiği (Zarit puanı artışı) belirlendi (Grafik 1).

Tablo 3. Bakılan Yaşlıya Ait Verilerin Bakım Veren Yükü Üzerine Etkisi

\begin{tabular}{|c|c|c|c|c|c|}
\hline Değişken & Grup & $\mathbf{N}$ & Zarit-Ortanca & Test ist. & $p$ \\
\hline \multirow[t]{3}{*}{ Yaş } & 65-74 yaş & 18 & $24(11-59)$ & $X^{2}=2,843$ & 0,241 \\
\hline & 75-84 yaş & 32 & $31,5(8-65)$ & & \\
\hline & $85+$ yaş & 24 & $23,5(11-60)$ & & \\
\hline \multirow[t]{2}{*}{ Cinsiyet } & Kadin & 46 & $26(11-63)$ & $Z=0,703$ & 0,482 \\
\hline & Erkek & 28 & $28(8-65)$ & & \\
\hline \multirow[t]{2}{*}{ Medeni durum } & Evli & 23 & $28(8-62)$ & $Z=-0,175$ & 0,861 \\
\hline & Dul & 51 & $26(11-65)$ & & \\
\hline \multirow[t]{4}{*}{ Eğitim } & Okur yazar değil & 46 & $29,5(12-65)$ & $X^{2}=4,988$ & 0,173 \\
\hline & Okur yazar & 8 & $21(11-47)$ & & \\
\hline & İlkokul & 15 & $20(8-60)$ & & \\
\hline & Ortaokul+lise & 5 & $25(14-55)$ & & \\
\hline \multirow[t]{2}{*}{ Sosyal güvence } & Var & 51 & $27(8-65)$ & $Z=-0,199$ & 0,842 \\
\hline & Yok & 23 & $24(11-63)$ & & \\
\hline \multirow[t]{2}{*}{ Kronik hastalık } & Var & 62 & $28(8-63)$ & $Z=-0,250$ & 0,803 \\
\hline & Yok & 12 & $23(16-65)$ & & \\
\hline \multirow[t]{2}{*}{ Engel durumu } & Var & 42 & $31,5(8-65)$ & $Z=2,506$ & $0,012 *$ \\
\hline & Yok & 32 & $21(11-60)$ & & \\
\hline \multirow[t]{2}{*}{ İnkontinans } & Var & 33 & $35(8-65)$ & $Z=2,585$ & $0,010^{*}$ \\
\hline & Yok & 41 & $23(11-61)$ & & \\
\hline
\end{tabular}

${ }^{*} 0,05$ dïzeyinde anlaml, Z: Mann Whitney U testi, $X^{2}$ : Kruskal Wallis testi 


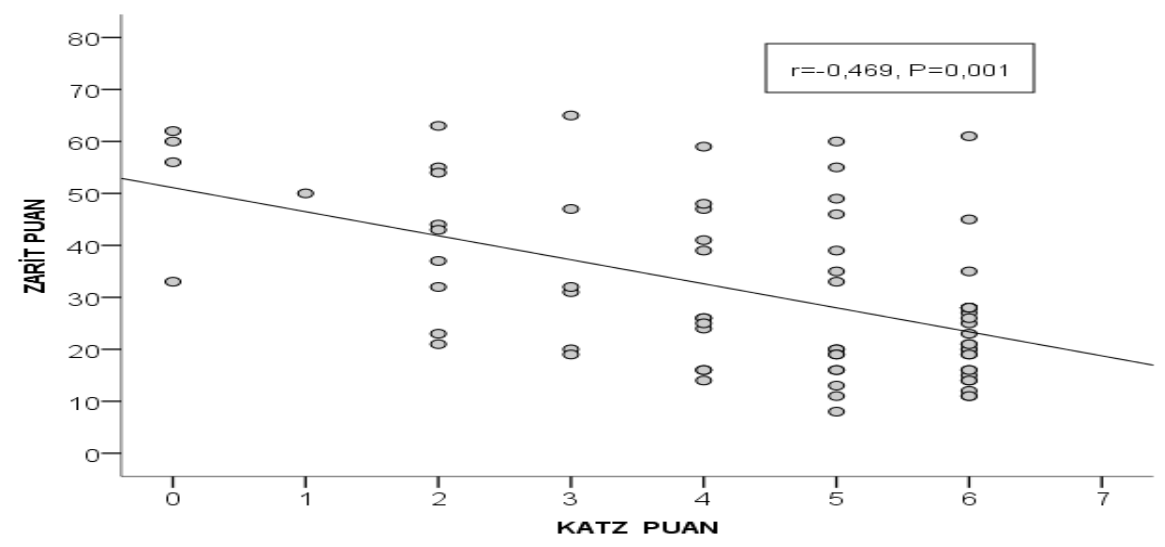

Grafik 1. Katz ve Zarit puanları arasındaki ilişkiyi gösteren saçılım grafiği.

\section{Tartışma ve Sonuç}

Bir ilçede yaşayan yaşlılara bakan aile üyelerinin bakım yüklerinin ve ilişkili faktörlerin belirlendiği çalışmamızda kullanılan ZBYÖ puan ortalaması 31,05 $\pm 15,81$ olarak bulundu. Bakım yükü ile ilişkili faktörler; bakım verenin sosyodemografik, sağlık ve sosyal verilerinin yanı sıra bakım alan yaşlının da sosyodemografik ve sağlık verileri olarak ortaya kondu. Ortaya çıkan bulgular ülkemizde ve dünyada yapılmış çalışmalar 1şığında tartışıldı.

Ülkemizdeki çalışmalara bakıldığında, Samsun'da bir hastanenin dahiliye ve cerrahi kliniklerinde çeşitli nedenlerle yatmakta olan 65 yaş üstü hastaların bakım veren yakınları ile yapılan bir çalışmada ZBYÖ

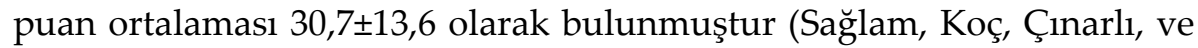
Korkmaz, 2016, s.52). Burdur ilinde 85 yaş ve üzeri kişilerin bakım verenleri ile yapılan epidemiyolojik bir çalışmada ZBYÖ puan ortalaması

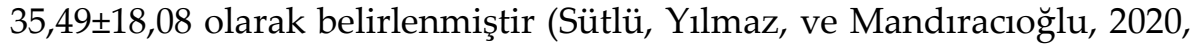
s.304). Afyonkarahisar ili Sinanpaşa ilçesinde yapılan çalışmada bakım yükü ortalaması 33,1 \pm 15 ,9 puan (Ay, Ünübol, Ezer, Omay, ve Sayar, 2017, s.40), İstanbul'da Sağlık İl Müdürlügüne kayıtlı ve evde bakım hizmeti alan yaşılıarın aile bireyleri ile yapılan çalışmada bakım yükü ortalaması 
38,48 $\pm 12,68$ puan (Erkan ve Altuntaş, 2019, s.595) olduğu bildirilmiştir. Bizim çalışmamız literatürlerle uyumluydu.

Ülkemizde bakım yükü yüksek çıkan çalışmalar bulunmaktadır. Samsun'da nöroloji polikliniğinde Alzheimer hastalarının bakım verenleri ile yapılan bir çalışmada ZBYÖ puan ortalamasının 42.356 \pm 20.26 olduğu (Altay, Erkuran, ve Aydın Avci, 2018, s.3), Kahramanmaraş'ın Çağlayancerit ilçesinde 65 yaş ve üstü bireylerin bakım verenleriyle yapılan çalışmada bakım yükü puan ortalamasının 59,76 olduğu bildirilmiştir (Korkut ve Gençtürk, 2019, s.58). Kronik hastalığ yaşlıların bakım verenlerindeki yükü belirlemek için hastalığından dolayı en az 5 gün hastanede yatan yaşlıların bakım verenleriyle yapılan bir

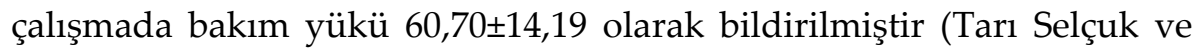
Avcı, 2016, s.3). Tarı Selçuk ve Avcı'nın çalışmasının en az bir kronik hastalığa sahip olan ve hastanede yatan yaşlıların bakım verenlerine yönelik olması, bakım yükü puanının yüksek çıkmasının nedeni olarak düşünüldü. Çalışmamız ise sahada, ev ortamında gerçekleştirildi.

Dünyadaki çalışmalara bakıldığında ise; Zarit Bakım Verme Yükü Ölçeğinin Japonya'da yaşayan yaşlılara bakım verenler için kullanımının geçerlilik ve güvenilirlik çalışmasında demans tanısı alan yaşlılara bakım verenlere uygulanmış, Japon bakım vericiler için uygun bulunmuş ve çalışmanın bakım yükü puan ortalaması 28.6 \pm 15.3 olarak bildirilmiştir (Hirono, Kobayashi, ve Mori, 1998, s.564). Başka bir çalışmada siroz hastalığı tanısı almış yaşlıların bakım verenlerinin bakım yükü puan ortalaması 27,93 olarak bulunmuştur (Shrestha vd., 2020, s.13). İtalya'da 13 ayrı bölgede yapılan epidemiyolojik bir çalışmada Parkinson tanısı alan yaşlılara bakım verenlerin yükleri ölçülmüş ve puan ortalaması 31,4 416,0 olarak bulunmuştur (Tessitore vd., 2018, s.1127). Hindistan'da demans hastası yaşlılara bakım verenlerin ZBYÖ puan ortalaması 47,7 iken, aynı çalışmada psikoz tanısı olan yaşlılara bakım verenlerde yük puanı ortalaması 33,6 olarak bulunmuştur (Sinha, Desai, Prakash, Kushwaha, ve Tripathi, 2017, s.89). Çalışmamız, yurtdışı çalışmalardaki literatürle de uyumlu bulundu.

Bakım verenlerin sosyodemografik verileri ile bakım yükü arasında ilişki incelendiğinde; yapılan araştırmalarda farklı sonuçların çıktığı bildirilmiştir (Ge ve Mordiffi, 2017, s.474). Bakım verenlerin yaşları ile bakım yükü arasındaki ilişkide; bakım verenin yaşının genç olmasının 
bakım yükünü artırdığını (Ge ve Mordiffi, 2017, s.475), bakım veren yaşı ile bakım yükü arasında herhangi bir ilişki olmadığını (Tarı Selçuk ve Avc1, 2016, s.4) ve bakım verenin yaşı ilerledikçe bakım yükünün arttığını (Jafari, Ebrahimi, Aghaei, ve Khatony, 2018, s.3) bildiren çalışmalar mevcuttur. Çalışmamızda ise bakım verenin yaşı arttıkça bakım yükünün de arttığ1 görüldü. Bakıma muhtaç eşlerine bakan ileri yaştaki bakım verenlerin yüksek ZBYÖ puanlarının bu sonuçta etkili olduğu düşünüldü.

Bakım verenlerin eğitim seviyeleri ile bakım yükü arasındaki ilişkide; eğitim seviyesinin bakım yükü üzerinde etkisi olmadığını bildiren kısıtlı sayıda çalışmaya rastlandı (Ge ve Mordiffi, 2017, s.475). Yapılan birçok araştırmada ise eğitim seviyesinin etkisi bildirilmiştir. İran'da yapılan bir çalışmada üniversite mezunlarına göre ilk ve ortaokul mezunlarının bakım yükü daha fazla bulunmuştur (Jafari, Ebrahimi, Aghaei, ve Khatony, 2018, s.4). Mısır'da yapılan bir çalışmada bakım verenlerin eğitim durumunun bakım yükü puanı üzerinde en önemli belirleyicilerden biri olduğu bildirilmiştir (Ghazawy, Mohammed, Mahfouz, ve Abdelrehim, 2020, s.4). Unver ve arkadaşları da ülkemizde yaptıkları bir çalışmada bakım verenlerin eğitim seviyelerinin bakım yükü puanları üzerindeki etkisini istatistiksel olarak göstermişlerdir (Unver, Basak, Tosun, Aslan, ve Akbayrak, 2016, s.169). Çalışmamızda genel literatürle uyumlu olarak bakım verenlerin eğitim seviyesi yükseldikçe bakım yüklerinin düştüğü tespit edildi. Bu bulgunun eğitim ve bilginin, insanların empati yeteneğini artırması, yaşlı bakım kalitesi ve genel yaşam tarzı üzerindeki olumlu etkisinden kaynaklanabileceği düşünüldü.

Bakım verenlerin yaşlı ile yakınlığı arasındaki ilişki incelendiğinde; ülkemizde yapılan bir çalışmada ikinci dereceden akrabaların (gelin, torun) bakım yükleri eş ve çocukların bakım yüklerinden yüksek bulunmuştur (Tarı Selçuk ve Avcı, 2016, s.4). Tarı Selçuk'un bu çalışması bir hastanede gerçekleştirilmiştir. Çalışmamızda ise tam tersi olarak dede veya ninesine bakan bakım verenlerde bakım yükü puanları en düşük çıktı. Bunun nedeni olarak çalışmamızın toplumda gerçekleştirilmiş olması, yaşlıya bakan torunların başka akrabalarının da yaşlıya bakımda destek vermesi ve yükü paylaşması olarak düşünülmektedir.

Bakım verenlerin sağlık durumları ile bakım yükü arasındaki ilişki incelendiğinde; Manisa'da evde bakım hizmeti alanların bakım verenleri 
ile yapılan bir çalışmada bakım verenin sağlık durumu ile bakım yükü arasında istatistiksel olarak anlamlı bir ilişkiden bahsedilmiş, bakım verenin sağlık durumu kötüleştikçe bakım yükünün de arttığ1 bildirilmiştir (Sögüt ve Erbay Dündar, 2017, s.43). İstanbul'da evde bakım hizmeti alan yaşlılara bakım veren aile bireylerinin dahil edildiği bir çalışmada, tanılanmış bir sağlık sorunu olan bakım verenin bakım yükünün yüksek olduğu gözlenmiştir (Erkan ve Altuntaş, 2019, s.594). Trakeostomi yapılan hastaların bakım verenlerinin dahil edildiği çalışmada ise bakım verenlerin kronik hastalık varlığının bakım yükünü de artırdığı bildirilmiştir (Karaca, Altinbas, ve Aslan, 2019, s.26). Bizim çalışmamızda literatüre uyumlu olarak kronik hastalığ1 olan bakım verenlerde bakım yükü, hastalığı olmayanlardan yüksekti. Ayrıca bakım verenlerin kronik hastalık sayısı arttıkça Zarit Bakım Verme Ölçeği puanları da artış gösterdi.

Uyku durumu ile bakım yükü arasındaki ilişki incelendiğinde; yapılan bir çalışmada uyku kaliteleri yüksek olan bakım verenlerin bakım yükü seviyelerinin düşük, uyku ilacı kullananların ise bakım yükü seviyelerinin yüksek olduğu ortaya konmuştur (Dağdeviren, Demir, Adahan, Dağdeviren, ve Tekin, 2020, s.190). Bizim çalışmada uykusuzluk çeken bakım verenlerde uyku sorunu olmayanlara göre bakım yükü yüksekti.

Sosyal hayatla bakım yükü arasındaki ilişki incelendiğinde; İspanya' da yapılan bir çalışmada yaşamlarında sosyal desteği yüksek olan bakım verenlerin Zarit yük puanları düşük olarak bulunmuştur (Muñoz Bermejo, Postigo Mota, Casado Verdejo, ve De Llanos Peña, 2015, s.56). İspanya Galiçya' da bakım yükünü artıran risk faktörlerinin belirlenmesi amacıyla yapılan başka bir çalışmada, yüksek sosyal desteğin düşük bakım yükü riski oluşturduğu ve ev dişında çalışmayan kişilerin de yüksek bakım yükü riski altında olduğu bildirilmiştir (Blanco vd., 2019, s.23). Başka bir çalışmada sosyal destek ve iyi aile ilişkilerinin bakım yükünü hafiflettiği ortaya çıarılmıştır (Yu, Wang, He, Liang, ve Zhou, 2015, s.7). Benzer şekilde bizim çalışmada; sosyal hayat olarak yürüyüş yapanlarda, bilgisayar kullananlarda, boş zamanlarında ailesi ile vakit geçirenlerde, evden dışarıya sıklıkla çıkanlarda ve çalışmak için dışarıya çıkanlarda bakım yükü istatistiksel olarak düşük bulundu.

Bakılan yaşlının bakıma muhtaçlığı ile bakım verenin bakım yükü arasındaki ilişki incelendiğinde; Sütlü ve arkadaşları tarafından 
Burdur'da yapılan çalışmada yaşlının bağımlılığı Katz Günlük Yaşam Aktiviteleri Ölçeği (Katz GYA) ile ölçülmüş, bağımlılığın artması (GYA ölçek puanının düşük olması) bakım yükünü artıran faktör olarak bildirilmiştir (Sütlü, vd., 2020, s.305). Manisa'da yapılan çalışmada yaşlının bağımlılık düzeyi ile bakım yükü arasındaki ilişki anlamlı bulunmuştur (Söğüt ve Erbay Dündar, 2017, s.43). Kronik hastalığ1 olan yaşlılarla yapılan çalışmada yaşlının bağımlılık durumu arttıkça (Katz GYA ölçeği puanı azaldıkça) bakım verenin yükünün de arttığı (Zarit Bakım Yükü Ölçeği puanı artması) bildirilmiştir (Tarı Selçuk ve Avcı, 2016, s.5). Yaşlının bağımlılığının Bartel Temel Günlük Yaşam Aktiviteleri Skalası kullanılarak ölçüldügü bir çalışmada Bartel puanındaki düşüş (bağımlılığın artması) ile bakım yükünün artması arasındaki ilişki istatistiksel olarak ortaya konmuştur (Unver vd., 2016, s.169). Sinanpaşa'daki çalışmada Günlük Yaşam Aktiviteleri puanına göre, tam bağımlı grubun bakım verenlerinde bakım yükü en yüksek, bağımsız grubun bakım verenlerinde ise bakım yükü en düşüktür. Bakım yükü puanı ile Günlük Yaşam Aktiviteleri puanı arasında istatistiksel açıdan anlaml ancak zayı bir ters korelasyon tespit edilmiştir ( $r h o=-0,33, p=0,01)$ (Ay vd., 2017, s.41). Benzer şekilde bizim çalışmada da Katz puanı ile Zarit puanı arasında negatif yönde orta düzeyde anlamlı bir korelasyon saptandı $(r=-0,469, P=0,001)$. Yaşlılardaki bağımlılığın artması bakım verenlerdeki yükü artırdı.

Yaşlının engel durumu ile bakım verenin yükü arasındaki ilişki incelendiğinde; bir çalışmada yaşlıda engel bulunmasının bakım verendeki yükü artırdığı belirtilmiştir (Ghazawy vd., 2020, s.7). Başka bir çalışmada inme sonrası hemipleji gelişmiş geriatrik hastalara bakım verenlerde Zarit Bakım Verme Yükü Ölçeği puanı 50,88ะ5,67 çıkmış, aynı çalışmada serebral palsili çocuklara bakım veren annelerde bakım yükü

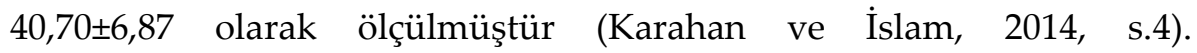
Çalışmamızda da yaşlının engelinin bulunması bakım verendeki yükü artırdi.

Yaşlıda üriner inkontinans bulunması ile bakım verenin yükü arasındaki ilişki incelendiğinde; Brezilya Sao Paulo'da yapılan bir çalışmada bakıcı yükü ile idrarını tutamayan hastalar arasında anlamlı bir pozitif ilişkinin olduğu, bunun da yaşlı hastalarda idrar tutamamanın daha fazla bakıcı yükü oluşturduğu bildirilmiştir (Tamanini, Santos, 
Lebrão, Duarte, ve Laurenti, 2011, s.1283). Başka bir çalışmada inkontinans durumu açısından tam bağımlı olan yaşlıların bakım verenlerinde bakım yükleri bağımsız olan yaşlıların bakım verenlerinin yüklerine göre daha yüksek bulunmuştur (Ay vd., 2017, s.41). Bizim çalışmada literatürle uyumlu olarak üriner inkontinansa sahip yaşlıların bakım verenlerinde bakım yükü yüksek olarak bulundu.

Çalışmanın sonuçları kendi içerisinde değerlendirildiğinde; 65 yaş ve üstünde olan çiftlerden birinin bakıma muhtaçlığı nedeni ile diğer eşin ona bakım vermesi durumu bakım yükünün en yüksek çıtığı olguları oluşturdu. Çalışmada yaşın ilerlemesi ile bakım yükü puanlarının artış göstermesinin nedeninin bu olduğu düşünüldü. Kendisi de geriatrik yaşta olan bakım veren eş, hem kendi yaşlılıkla ilgili sorunları ile baş ederken hem de bakıcı rolü ve sorumluluğu ile baş etmekteydi. Çalışan bakım verenlerde ve evinden dışarıya sıklıkla çıkabilen bakım verenlerde yükün düşük olması tartışılması gereken diğer bulgulardı. Bu bakım verenlerin evden ayrıldıklarında yaşlılarını yalnız bırakmayacak başka imkanlara sahip olduğunu gösteriyordu. İlçede bir gündüz bakım destek merkezinin açılmasının, ileri yaşta olan bakım verenler ile dışarıya çıtıklarında yaşlılarını emanet edecek kimse olmayan bakım verenler için yüklerini azaltacak çok önemli bir hizmet olacağı rapor edildi. Çalışmada bilgisayar kullananlarda yükün hafif olması, uyku problemi yaşayanlarda yükün yüksek çıkması bulgularından yola çıkarak ilçede bilgisayar kursları açılması, kurumlar bünyesinde bir yaşlı destek merkezi kurulması ve bu merkezde bir gerontology, psikolog veya sosyal hizmet uzmanı bulundurulması gibi hizmetleri hayata geçirmeleri kurumlara tavsiye edildi.

Kısıtlılıkları: Bu çalışmanın bazı kısıtlılıkları vardı. Birincisi ilçede yaşlıya bakım veren kişi sayısı bilinmiyordu ve bakım verenlerin kayıtlı olduğu herhangi bir kurum veya sivil toplum kuruluşu mevcut değildi. Kaymakamlık Sosyal Yardımlaşma ve Dayanışma Vakfı'na kayıtlı çok sayıda yaşlı bulunmasına rağmen bunların çoğunluğu yalnız yaşayan yaşlılardan oluşuyordu. Vakıf, yalnız yaşayan ve maddi durumu iyi olmayan yaşlılara yemek ve temizlik hizmeti götürüyordu. Vakıfa kayıtlı "bakım maaşı" alan 22 kişi bulunuyordu ancak bunların sadece 9 kişisi yaşlıya bakım verenlerden oluşuyordu. Aile hekimliği kişisel verilerin 
korunması gereği bir veri paylaşmadı. Belediyenin de elinde bir kayıt yoktu. Çalışmada, bakım verenlere Eldivan Kaymakamlı̆̆ı desteği ile mahalle muhtarlarından yardım alarak ulaşıldı. Bunun dışında, çalışmanın tam ortasında COVID-19 pandemisi nedeniyle yaşlılara sokağa çıkma yasağ kalındı. Maske-mesafeye dikkat edilerek ve genellikle evlerin bahçesinde açık havada görüşmeler yapılmasına rağmen bazı katılımcıların COVID19 kaygısı ile çalışmaya dahil olmadıkları (4 katılımcı) görüldü. Muhtarların, ilçede bakım verenlerin büyük bir çoğunluğuna ulaşıldığ 1 bildirimlerinden yola çıkarak, tüm bu kısıtlılıkların çalışmanın sonuçları üzerinde bir etkisinin olmadığı düşünüldü. Çalışma bir ilçedeki yaşlılara bakım verenler ile gerçekleştirildiğinden dolayı ortaya çıkan sonuçların tüm topluma genellenemeyeceğini belirtmeliyiz.

Topluma Katkıları: Bu çalışmanın alana akademik katkılarının yanında önemli sosyal ve toplumsal katkıları da vardı. En önemlisi ilçede böyle bir çalışmanın ilk defa yapılıyor olmasıydı. Çalışma bir üniversitenin Bilimsel Araştırmalar Projesi (BAP) kapsamında üniversite ile kaymakamlık iş birliğinde gerçekleştirildi. Çalışma sonucunda ortaya çıkan raporla ilçede hem kurumların hem de toplumun yaşlı bakımına yönelik farkındalığı artırıldı. İlçede yaşlı bakımına yönelik sivil toplum örgütlerine ve belediye hizmetlerine ihtiyaç duyulduğu ortaya koyuldu. Çalışmanın akademik bulgularında yer almayan ancak, içerisinde gündüz yaşlı bakımı hizmetinin yürütüldüğü, fizyoterapi uygulamalarının bulunduğu, yaşlılara sosyal aktivitelerin yaptırıldığı ve böylece bakım verenlerin yükünün hafifletildiği bir aile destek merkezinin kurulması katılımcılar tarafından bir talep olarak dile getirildi $(\% 83,6)$.

Sonuç olarak bu çalışmada; ileri yaşta olan, eğitim seviyesi düşük olan, kronik hastalığı bulunan, kronik hastalık ve kullanılan ilaç sayısı fazla olan, uyku problemi yaşayan ve bir işte çalışmıyor olan bakım verenlerde bakım yükü yüksek, evden sık sık dışarıya çıkan, düzenli yürüyüş ve spor yapan, ailesi ile vakit geçiren ve bilgisayar kullanan bakım verenlerde bakım yükü düşük olarak bulundu. Yatalak olan, bir engeli bulunan ve idrarını tutamayan (inkontinans) yaşlılara bakım verenlerde bakım yükü yüksek olarak bulundu. Yaşlının bağımlılı̆̆ı artış gösterdikçe bakım verenin yükünün de artırdığı tespit edildi. 
EXTENDED ABSTRACT

\title{
Care Burden of Informal Caregivers of the Elderly Living in Eldivan District
}

\author{
Tahsin Barış Değer- Yadigar Ordu \\ Çankırı Karatekin University
}

The meaning of the word care is defined as effort expended to improve something or continue in the best way, and the work of providing support in completing daily life activities like eating and dressing. The caregiver is defined as the person providing this support to the elderly person requiring care. Here support may be emotional support, but may include shopping, doing housework, routine health care like coordinating the assistance provided by experts for the elderly person and administering medications, personal care like bathing, eating, toileting and dressing, supervising, financial assistance, and sharing a common home. Caregiving is divided in two as formal and informal. Formal care is care provided by members of the profession giving health or social care services at home or in care centers. These include nurses, physiotherapists, social workers or elderly care technicians. Informal care is care given by the partner, children, relatives or neighbors of the elderly person requiring care.

Caregiving is an experience with both positive and negative dimensions in terms of individuals who provide care to elderly people. Positive aspects include features like increased love and commitment between the elderly person and caregiver, praise from people around, and feeling good in emotional terms. Negative aspects include stress and physical discomfort in the caregiver, inability to participate in social life, inability to take time for themselves, disrupted relationships with family members and difficulties in economic and working life. The care burden is defined as discomfort experienced in health, psychological, social and economic terms by the family member caring for the elderly individual.

With the rapid increase in the number of elderly people in the world and in Turkey in recent years, the topic of elder care has become more important. According to population projections, the increase in the 
proportion of elderly people in the whole population is reported to continue rapidly. One of the most important indicators of these projections is the prediction that the elderly dependence rate which was $12.9 \%$ in 2018 will reach $43.6 \%$ in 2080 . The elderly dependence rate represents the ratio of the elderly population to the employed population. The increase in this ratio means that the number of elderly people requiring care will increase in the future and the duration of care will increase, which will lead to increased requirements for caregivers.

In this study, the aim was to determine the care burden and factors affecting this burden for informal (family members) caregivers of elderly people living in Eldivan county in Çankırı. In addition to contributing to the literature, a target of this study is to guide institutions about services to be planned for elderly people and their caregivers in similar counties in Anatolia.

Caregivers for individuals aged 65 years and older living in the county were accessed with the aid of neighborhood headman. Studies were completed with face-to-face survey interviews. In total, a sample of 74 elderly people and 74 caregivers living in the county was created. The study was designed to be cross-sectional. The study began in March of 2020; however due to the COVID-19 pandemic and the declaration of a curfew for elderly people in Turkey from 21 March 2020, the study had to be postponed. When the curfew for elderly people was lifted in the summer months, the study continued in August and September and the study was completed in a total of two months. The study was completed by paying attention to masking, distance and hygiene rules with elderly people and their caregivers. Interviews were held in the gardens of houses, in the open air.

In the study, the Zarit Caregiver Burden Scale (ZCBS) for the caregiver and Katz Activities of Daily Living Scale for the elderly were used. The care burden for the caregiver was identified with the ZCBS. This scale, with Turkish validity and reliability studies performed, has points from 0 88 with 22 Likert-type questions and high points showing high degree of care burden. The Katz Activities of Daily Living Scale for the elderly individual measured their dependence level. Points are 0-6 and the scale contains six questions, with low points on the scale indicating increased dependence of the elderly person. Apart from these scale tools, 
sociodemographic, health and social data along with hobbies, lifestyle, family relationships and habits were recorded for the caregiver, while sociodemographic and health data were recorded for the elderly individuals. The dependent variable in the study was the ZCBS points of the caregiver. Comparison of two categories used the Mann Whitney U test, while comparison of more than two categories used the Kruskal Wallis multiple comparison test.

In the study mean ZCBS points were determined as $31.05 \pm 15.81$ and it was identified that caregivers for elderly in the county had mildmoderate degree of care burden. The median value for ZCBS points was 26.5 (8-65). The care burden for those caring for elderly with older ages was higher compared to those caring for younger elderly. The care burden for participants who were university graduates was lower compared to participants with other educational levels. Those who graduated from high school and primary education had lower care burden compared to those who were illiterate. The care burden of those caring for partners was higher than those caring for mother, father, mother-in-law, father-in-law, grandfather or grandmother. The highest care burden was for those caring for bedridden elderly people, while care burden was higher for those caring for disabled elderly or those who need it compared to other reasons for caring (Table 1). The care burden for participants with chronic disease was higher compared to those without chronic disease. The care burden for participants who used two or more medications regularly every day was higher compared to those who did not use medication. Care burden was higher for those with insomnia compared to those without sleep problems. For caregivers who were unemployed, the care burden was higher compared to those who worked. Participants who couldn't use computers had higher care burden than those who could. Those who left the house frequently, did regular walks or sport, and spent free time with family were determined to have lower care burden (Table 2). When the effect of data related to the elderly person is investigated for the effect on care burden, caregivers for elderly people with disabilities had higher care burden than those caring for elderly without disability. The care burden for caregivers of elderly people with incontinence (urinary) was high compared to caregivers for elderly people without incontinence (Table 3). There was a negative and moderate significant correlation identified 
between the ZCBS points for caregivers and the Katz scale points for elderly people $(\mathrm{r}=-0.469, \mathrm{P}=0.001)$. As the dependence level of elderly increased (Katz points reduced), the care burden for caregivers increased (Zarit points increased) (Graph 1). The study provides academic contribution to the field in addition to significant social and societal contributions. Awareness about elderly people and caregivers in the county increased and it acted as a guide for institutions.

\section{Kaynakça / References}

Altay, B., Erkuran, H. ve Aydın Avci, İ. (2018). Alzheimerlı hastaya bakım verenlerin bakım yükü ve etkileyen faktörler. Samsun Să̆llk Bilimleri Dergisi, 3(2), 1-8.

Arik, G., Varan, H. D., Yavuz, B. B., Karabulut, E., Kara, O., Kilic, M. K., ... Cankurtaran, M. (2015). Validation of Katz index of independence in activities of daily living in Turkish older adults. Archives of Gerontology and Geriatrics, 61(3), 344-350.

Ay, S., Ünübol, H., Ezer, S., Omay, O. ve Sayar, G. (2017). Evaluation of the relationship between caregiver burden, coping styles and levels of anxiety and depression in caregivers of old age patients. Family Practice and Palliative Care, 2(3), 38-44.

Blanco, V., Guisande, M. A., Sánchez, M. T., Otero, P., López, L. ve Vázquez, F. L. (2019). Síndrome de carga del cuidador y factores asociados en cuidadores familiares gallegos [Caregiver burden and associated factors in family caregivers in the Community of Galicia, Spain]. Revista Espanola de Geriatria y Gerontologia, 54(1), 19-26.

Bostan, H. ve Sertkaya Doğan, Ö. (2019). Türkiye'nin demografik dönüşümü ve nüfus projeksiyonlarına göre firsatlar. Doğu Coğrafya Dergisi, 24(41), 6190.

Chan, S. W. C. (2010). Family caregiving in dementia: The Asian perspective of a global problem. Dement Geriatr Cogn Disord, 30, 469-478.

Dağdeviren, T., Demir, N., Adahan, D., Dağdeviren, M. ve Tekin, O. (2020). Evde sağlık hizmeti alan hastaların bakım verenlerinde bakım yükü. Turkish Journal of Family Medicine and Primary Care, 14(2), 186-195.

Erdem, M. (2010). Yaşlıya bakım verme. Anadolu Hemşirelik ve Sağlık Bilimleri Dergisi, 8(3), 101-106.

Erkan, H. ve Altuntaş, M. (2019). Evde sağlık hizmeti alan hastalarda bakım yükünün değerlendirilmesi. Ankara Medical Journal, 19(3), 591-601. 
Ge, L. ve Mordiffi S. Z. (2017). Factors associated with higher caregiver burden among family caregivers of elderly cancer patients: a systematic review. Cancer Nurs, 40(6), 471-478.

Ghazawy, E. R., Mohammed, E. S., Mahfouz, E. M., ve Abdelrehim, M. G. (2020). Determinants of caregiver burden of persons with disabilities in a rural district in Egypt. BMC Public Health, 20(1), 1156.

Hirono, N., Kobayashi, H. ve Mori, E. (1998). Caregiver burden in dementia: evaluation with a Japanese version of the Zarit caregiver burden interview. No To Shinkei, 50(6), 561-567.

Honea, N. J., Brintnall, R., Given, B., Sherwood, P., Colao, D. B., Somers, S. C. ve Northouse, L. L. (2008). Putting Evidence into Practice: Nursing assessment and interventions to reduce family caregiver strain and burden. Clinical Journal of Oncology Nursing, 12(3), 507-516.

İnci, F. (2006). Bakım Verme Yükü Ölçeği'nin Türkçe'ye uyarlanması, geçerlilik ve güvenilirliği. (Yüksek Lisans Tezi). Pamukkale Üniversitesi, Sağlık Bilimleri Enstitüsü, Halk Sağlığı Hemşireliği Anabilim Dalı, Denizli.

İnci, F. H. ve Erdem, M. (2008). Bakım verme yükü ölçeğinin Türkçe'ye uyarlanması, geçerlilik ve güvenilirliği. Atatürk Üniversitesi Hemşirelik Yüksekokulu Dergisi, 11(4), 85-95.

Jafari, H., Ebrahimi, A., Aghaei, A., ve Khatony, A. (2018). The relationship between care burden and quality of life in caregivers of hemodialysis patients. BMC Nephrology, 19(1), 321.

James, K., Thompson, C., Holder Nevins, D., Donaldson Davis, K., WillieTyndale, D., McKoy Davis, J., ... Eldemire-Shearer, D. (2021). Sociodemographic, Health and Functional Status Correlates of Caregiver Burden Among Care Recipients Age 60 Years and Older in Jamaica. Journal of Community Health, 46(1), 174-181.

Karaca, T., Altinbas, Y. ve Aslan, S. (2019). Caring for patients with a tracheostomy at home: A descriptive, cross-sectional study to evaluate health care practices and caregiver burden. Wound Management \& Prevention, 65(3), 22-29.

Karahan, A. ve İslam, S. (2014). Fiziksel engelli çocuk ve yaşlı hastalara bakım verme yükü üzerine bir karşılaştırma çalışması. Clinical and Experimental Health Sciences, 3(5), 1-7.

Katz, S. (1983). Assessing self maintenance: Activities of daily living, mobility and instrumental activities of daily living. JAGS, 31(12), 721-726. 
Korkut, G. ve Gençtürk, Z. (2019). Yaşlilara bakım veren aile bireylerinde algılanan bakım yükü ve yaşam doyumu arasındaki ilişkinin değerlendirilmesi. Uluslararası Sosyal Bilimler Akademik Araştırmalar Dergisi, 3(3), 53-78.

Misra, S., Oswal, R. ve Patel, M. (2020). Family burden in caregivers of elderly with cognitive impairment residing in rural and tribal population of a district in Western India - A baseline study. Indian Journal of Community Medicine: Oofficial Publication of Indian Association of Preventive $\mathcal{E}$ Social Medicine, 45(4), 445-447.

Muñoz Bermejo, L., Postigo Mota, S., Casado Verdejo, I., ve De Llanos Peña, F. (2015). El cuidador mayor de personas mayores. Sobrecarga y apoyosocial [elderly caregivers of elderly people: burden and social support]. Revista de Enfermeria (Barcelona, Spain), 38(12), 52-58.

Pehlivanoğlu, E. F. Ö., Özkan, M. U., Balcığlu, H., Bilge, U., Ünlüoğlu, İ. (2018). Yaşlılar için Katz Günlük Yaşam Aktiviteleri Ölçeği'nin Türkçe' ye uyarlanması ve güvenilirliği. Ankara Med J, 2, 219-223.

Sağlam, Z., Koç, Z., Çınarlı, T. ve Korkmaz, M. (2016). Altmışbeş yaş ve üzeri bireylere bakım veren hasta yakınlarının bakım verme yükü ile etkileyen faktörlerin belirlenmesi. Samsun Sağlık Bilimleri Dergisi, 1(2), 40-60.

Shrestha, D., Rathi, S., Grover, S., Taneja, S., Duseja, A., Chawla, Y. K. ve Dhiman, R. K. (2020). Factors Affecting Psychological Burden on the Informal Caregiver of Patients with Cirrhosis: Looking Beyond the Patient. Journal of Clinical and Experimental Hepatology, 10(1), 9-16.

Sinha, P., Desai, N. G., Prakash, O., Kushwaha, S. ve Tripathi, C. B. (2017). Caregiver burden in Alzheimer-type dementia and psychosis: A comparative study from India. Asian Journal of Psychiatry, 26, 86-91.

Sögüt, Ç. ve Erbay Dündar, P. (2017). Evaluation of caregivers' burden of the patients receiving home health service in Manisa. Turkish Journal of Public Health, 15(1), 37-46.

Soysal, P. (2017). Günlük yaşam aktiviteleri. A. T. Iş̧k ve P. Soysal (Ed.), Geriatri Pratiğinde Ölçekler içinde, (s.34). İstanbul: İstanbul Tip Kitapevleri Yayıncllık, 1. Baskı.

Sütlü, S., Yılmaz, M. ve Mandıracıoğlu, A. (2020). Identifying the caregiver burden for the elderly population aged $\geq 85$ years in a province. Ege Tip Dergisi, 59(4), 302-309. 
Tamanini, J. T., Santos, J. L., Lebrão, M. L., Duarte, Y. A. ve Laurenti, R. (2011). Association between urinary incontinence in elderly patients and caregiver burden in the city of Sao Paulo/Brazil: health, wellbeing, and ageing study. Neurourology and Urodynamics, 30(7), 1281-1285.

Tarı Selçuk, K. ve Avcı, D. (2016). Kronik hastalığa sahip yaşlılara bakım verenlerde bakım yükü ve etkileyen etmenler. Süleyman Demirel Üniversitesi Sağllk Bilimleri Dergisi, 7(1), 1-9.

Tessitore, A., Marano, P., Modugno, N., Pontieri, F. E., Tambasco, N., Canesi, M., ... Antonini, A. (2018). Caregiver burden and its related factors in advanced Parkinson's disease: Data from the PREDICT study. Journal of Neurology, 265(5), 1124-1137.

Toseland, R.W., Smith, G., McCallion, P. (2001). Family Caregivers of the frail Elderly. A. Gitterman (Ed.), Handbook of social work practice with vulnerable and resilient populations içinde (s.548-581). New York, Columbia University Press, Second Edition.

Türk Dil Kurumu Sözlükleri. 05 Nisan 2021 tarihinde http://sozluk.gov.tr adresinden erişildi.

Türken Gel, K. ve Tokur Kesgin, M. (2017). İnformal bakım verenlerin bakım yüküne ilişkin hemşirelerin görüşleri. Anadolu Hemşirelik ve Sağllk Bilimleri Dergisi, 20(4), 267-278.

Unver, V., Basak, T., Tosun, N., Aslan, O. ve Akbayrak, N. (2016). Care burden and self-efficacy levels of family caregivers of elderly people in Turkey. Holistic Nursing Practice, 30(3), 166-173.

Uşarel, C. ve Işık, A. T. (2017). Bakıcı tükenmişliği. A. T. Işık ve P. Soysal (Ed.), Geriatri Pratiğinde Ölçekler içinde, (s.206). İstanbul: İstanbul Tip Kitapevleri Yayıncılık, 1. Baskı.

Yu, H., Wang, X., He, R., Liang, R. ve Zhou, L. (2015). Measuring the caregiver burden of caring for community-residing people with Alzheimer's disease. PloS One, 10(7), e0132168.

Zarit, S. H., Reever, K. E. ve Bach-Peterson, J. (1980). Relatives of the impaired elderly: Correlates of feelings of burden. Gerontologist, 20, 649-655. 


\section{Kaynakça Bilgisi / Citation Information}

Değer, T. B. ve Ordu, Y. (2021). Eldivan ilçesinde yaşayan yaşlılara informal bakım verenlerin bakım yükleri. OPUS- Uluslararası Toplum Araştırmaları Dergisi, 18(43), 6764-6789. DOI: 10.26466/opus.926095. 